erative administrated bupivacaine (0.125\%) had no benefit in ... splanchnic perfusion, ... in patients undergoing abdominal aortic surgery." We measured only endothelin, ANP, renin, epinephrine, norepinephrine and $A D H$. These remained almost unchanged in patients receiving $E A$. It is not implied that $E A$ is unable to optimize splanchnic perfusion in patients without vascular pathology and in other types of surgery that do not require aortic cross-clamping. Also, we did not suggest that EA is worthless in aortic surgery as it optimizes postoperative pain therapy. There surely was an intraoperative analgesic effect of our lumbar catheters, as shown by a significantly lower fentanyl consumption in the epidural group.

Finally, we would like to add that although thoracic $E A$ is used for several procedures at our institution, we do not consider it appropriate for abdominal aortic surgery where the need for intraoperative in heparin may increase the rate for neurological complications.

S.N. Piper MD

W.H Maleck MD

J. Boldt MD

Ludwigshafen, Germany

References

I Smeets HJ, Kievit J, Dulfer FT, van Kleef JW.

Endocrine-metabolic response to abdominal aortic surgery: a randomized trial of general anesthesia versus general plus epidural anesthesia. World J Surg 1993; 17: 601-7.

2 Gold MS, deCrosta D, Rizzuto C, Ben-Harari RR, Ramanathan $S$. The effect of lumbar epidural and general anesthesia on plasma catecholamines and hemodynamics during abdominal aortic aneurysm repair. Anesth Analg 1994; 78 :225-30.

3 Brinkmann A, Seeling $W$, Wolf CF, et al.. Einfluß der thorakalen Epiduralanästhesie auf die Pathophysiologie des Eventerationssyndroms. Anaesthesist 1994; 43: $235-44$.

4 Norman JG, Fink GW. The effects of epidural anesthesia on the endocrine response to major surgical stress: a randomized prospective trial. Am Surg 1997; 63: 75-80.

5 Väisänen O, Parviainen I, Ruokonen E, et al. Epidural analgesia with bupivacaine does not improve tissue perfusion after aortic reconstruction surgery. Br J Anaesth 1998; 81: 893-8.

\section{Good advice on airways, but measure- ments are not parameters}

To the Editor:

Hung and Mills' editorial ${ }^{1}$ about predicting difficult intubation was useful, but it is a shame they misused their terms. Karkouti et $a l^{2}{ }^{2}$ correctly referred throughout to measures and variables; Hung and Mills wrote "no single airway parameter". Hung and Mills then wrote of the analysis identifying "three simple bedside tests... as [the] most useful airway parameters to predict ...". They should have written "three simple bedside tests... as the most useful to predict ...", and they confused meanings more by writing in the very next sentence that the investigators compared their predictions "in terms of three parameters". These were not, as one might suppose at first reading, the three tests, but instead the positive predictive value, sensitivity, and specificity, which are technically proportions, but more loosely statistics.

Hung and Mills are not alone in using parameter incorrectly. ${ }^{3}$ They will not be the last, but that does not stop the usage being unwise. According to dictionaries, variable is one of the meanings of parameter, but scientists need to be more precise. A word such as parameter, which can used for almost anything that can be measured or calculated even if only vaguely and risks being a scientific thingummy (or, in French, le machin) - is best avoided except when it is unambiguously correct. Otherwise we will need to find a new word when we speak of the parameters of the normal distribution (the mean and standard deviation) and of clearance, half-life and volume of distribution as pharmacokinetic parameters.

Neville W Goodman DPHIL FRCA

Bristol, UK

References

1 Hung O, Mills J. Predictions and clinical decisions: a fine balance. Can J Anesth 2000; 47: 721-4.

2 Karkouti K, Rose K, Wigglesworth D, Cohen MM. Predicting difficult intubation: a multivariable analysis. Can J Anesth 2000; 47: 730-9.

3 Goodman NW. Paradigm, parameter, paralysis of mind. Br Med J 1993; 307: 1627-9.

REPLY:

We would like to thank Dr. Goodman for his comments. Generally, in the field of statistics, one usually thinks of a parameter as being linked to a particular model. In the third paragraph of our editorial which Dr. Goodman 
has critiqued, we are not referring to a particular statistical model and consequently (but perhaps ambiguously) using "parameter" synonymously with "measurement". For the sake of clarity we would therefore be content to replace "parameter" with "measurement" in the locations Dr. Goodman has highlighted.

Orlando Hung MD

Joanna Mills MD

Halifax, Nova Scotia

\section{Convulsions after the administration of high dose ropivacaine following an interscalenic block}

To the Editor:

Mardirosoff et al. describe the occurrence of convulsions after the administration of high dose ropivacaine following an interscalene block. ${ }^{1}$ This interesting case merits further documentation and comments to increase its educational value. The delay of $20 \mathrm{~min}$ between the end of the administration of ropivacaine and the convulsions argues against an iv injection. Therefore, it will be interesting to know if the authors observed premonitory signs (such as dizziness or incoherent speech) before convulsions. Indeed, it seems the sequence of the different phases of central nervous system intoxication are better individualized with ropivacaine, ${ }^{2}$ which is usually not the case with bupivacaine. Furthermore, did the authors make a second blood drug measurement in order to build a pharmacokinetic model and, by extrapolation, estimate the ropivacaine blood concentration at the time of the convulsions? In a case reported previously with severe cardiac toxicity after sciatic block with ropivacaine, ${ }^{3}$ we evaluated by extrapolation the total and unbound plasma concentration of ropivacaine to be 8.8 and 1.8 $\mathrm{mg} \cdot \mathrm{L}^{-1}$ respectively, at the time of the critical event. Indeed, a "grey" zone remains between the appearance of central nervous system toxicity and slight changes in EEG recordings with venous total plasma concentration of ropivacaine of $2.2 \mathrm{mg} \cdot \mathrm{L}^{-1}$ (range 0.5-3.2) as reported by Knudsen et al. ${ }^{4}$ and the development of severe cardiac toxicity. The ropivacaine plasma concentrations in Mardirosoff's case together with ours ${ }^{3}$ and those known in the literature ${ }^{4,5}$ could add valuable information.

G. Ekatodramis MD

A. Borgeat MD

Zurich, Switzerland

\section{References}

1 Mardirosoff C, Dumont L. Convulsions after the administration of high dose ropivacaine following an interscalenic block. Can J Anesth 2000; 47: 1263.

2 Klein SM, Benveniste H. Anxiety, vocalization and agitation following peripheral nerve block with ropivacaine. Reg Anesth Pain Med 1999; 24: 175-8.

3 Ruetsch $\Upsilon$ A, Fattinger KE, Borgeat A. Ropivacaineinduced convulsions and severe cardiac dysrhythmia after sciatic block. Anesthesiology 1999; 90: 1784-6.

4 Knusden K, Beckman Suurküla M, Blomberg S, Sjövall $J$, Edvardsson J. Central nervous and cardiovascular effects of i.v. infusions of ropivacaine, bupivacaine and placebo in volunteers. Br J Anaesth 1997; 78: 507-14. 5 Scott DB, Lee A, Fagan D, Bowler GMR, Bloomfiled P, Lundh $R$. Acute toxicity of ropivacaine compared with that of bupivacaine. Anesth Analg 1989; 69: 563-9.

\section{REPLY:}

We thank Ekatodramis and Borgeat for their interesting comments.

We did not observe any premonitory signs before the convulsions took place; neither did we perform a second blood drug measurement.

Nevertheless, unlike the case they reported, the total venous concentration at the time of convulsions was probably lower than $2.09 \mathrm{mg} \cdot \mathrm{L}^{-1}$ which, in our case, was the concentration measured one hour after the injection. Indeed, studies on ropivacaine pharmacodynamics suggest that 45 to $60 \mathrm{~min}$ is the average time to achieve maximal plasma concentrations after a plexus block or a wound infiltration. ${ }^{2,3}$ The $2.09 \mathrm{mg} \cdot \mathrm{L}^{-1}$ concentration measured in our patient is consistent with concentrations observed in the aforementioned studies, in which such severe central nervous system (CNS) toxicity was not observed.

Moreover, Scott showed that the rate of absorption was better correlated with CNS toxicity than the peak plasma concentration. ${ }^{4}$ This might also constitute another causal factor in our case, since a faster rate of local anesthetic absorption has been demonstrated in patients with chronic renal failure. ${ }^{5}$

C. Mardirosoff MD

L. Dumont MD

Annemasse, France

\section{References}

1 Ruetsch YA, Fattinger KE, Borgeat A. Ropivacaineinduced convulsions and severe cardiac dysrythmia after sciatic block. Anesthesiology 1999; 90: 1784-6.

2 Hickey R, Blanchard J, Hoffman J, Sjovall J, Ramamurthy $S$. Plasma concentrations of ropivacaine 